\title{
Esophageal squamous cell carcinoma and adenocarcinoma: At the Gates of Mordor
}

\author{
Jules Lin, MD
}

\footnotetext{
From the Section of Thoracic Surgery, Department of Surgery, University of Michigan Medical Center, Ann Arbor, Mich.

Disclosures: Author has nothing to disclose with regard to commercial support.

Received for publication July 22, 2017; accepted for publication July 31, 2017.

Address for reprints: Jules Lin, MD, Section of Thoracic Surgery, 1500 E Medical Center Drive, 2120TC/5344, Ann Arbor, MI 48109-5344 (E-mail: juleslin@umich.edu).

J Thorac Cardiovasc Surg 2017;154:1444-5

$0022-5223 / \$ 36.00$

Copyright (C) 2017 by The American Association for Thoracic Surgery

http://dx.doi.org/10.1016/j.jtcvs.2017.07.048
}

Historically, esophageal squamous cell carcinoma (ESCC) and esophageal adenocarcinoma (EAC) have been grouped together even with differences in risk factors, demographics, and histopathology. Lagisetty and colleagues ${ }^{1}$ highlight findings from the Cancer Genome Atlas Research Network identifying distinct molecular differences between ESCC and EAC. ${ }^{2}$ They found that EAC was more similar to gastric adenocarcinomas with chromosomal instability (CIN) than to ESCC and cautioned against performing trials combining ESCC and EAC.

Although the CROSS Trial is cited to support neoadjuvant chemoradiation for both ESCC and EAC, ${ }^{3}$ Lagisetty and colleagues ${ }^{1}$ point out that differences in complete pathologic response ( $49 \%$ vs $23 \%$ ) may be due to genomic differences. The survival benefit was driven by the ESCC subgroup (hazard ratio, $0.422 ; P=.007$ ), whereas survival for EAC did not reach significance (hazard ratio, 0.741; $P=.07)$. They also suggest that grouping EACs with gastroesophageal and gastric adenocarcinomas, similar to the MAGIC trial that evaluated perioperative chemotherapy before and after esophagectomy, may be more appropriate than grouping ESCC with EAC. ${ }^{4}$

Should ESCC be treated like oropharyngeal squamous cell carcinomas and EACs treated like gastric adenocarcinomas? Should gastric adenocarcinomas be treated with preoperative chemoradiation? The treatment of ESCC and EAC is separated in the National Comprehensive Cancer Network guidelines. ${ }^{5}$ For ESCC, definitive chemoradiation followed by surveillance is an alternative (category 2B), whereas preoperative chemoradiation is an alternative (category 2B) to perioperative chemotherapy for gastric cancer. ${ }^{6}$ Although neoadjuvant chemoradiation is listed as preferred for EAC (category 1), neoadjuvant and perioperative chemotherapy are alternatives, but this remains controversial with some advocating for neoadjuvant chemotherapy alone. ${ }^{7}$ Several studies have shown a survival advantage with neoadjuvant chemotherapy or chemoradiation compared with surgery alone and higher pathologic complete response with chemoradiation, but a

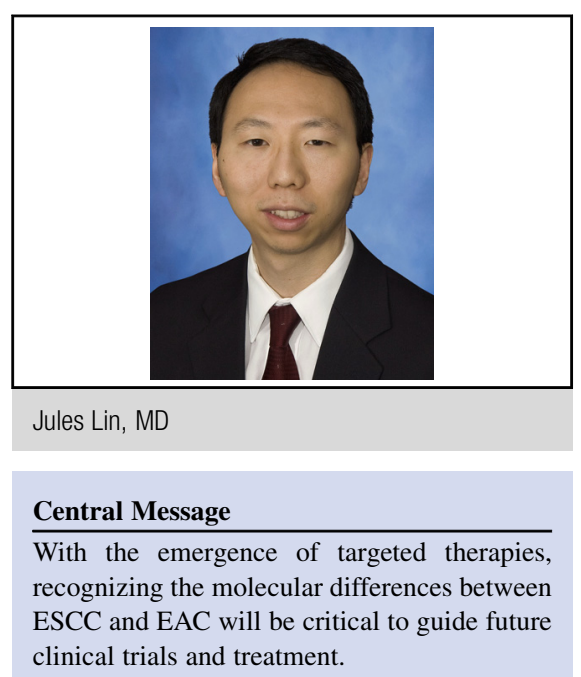

See Article page 1446. difference in survival between chemoradiation and chemotherapy has not been definitively demonstrated. ${ }^{3,4,8}$ Randomized trials comparing preoperative chemotherapy to chemoradiation are in progress (ESOPEC Trial NCT02509286).

Although treating EACs and gastric cancers similarly seems reasonable, EAC was only similar to CIN gastric cancers and not the gastric Epstein-Barr virus, microsatellite instability, or genetically stable groups. There was also more DNA methylation in EACs than gastric CIN cancers. For copy number changes, EAC was more similar to ESCC and gastric CIN than non-CIN cancers. EACs also have increased rapidly in Western countries, have a different epidemiology, and have an inverse relationship to Helicobacter pylori in contrast to gastric cancer.

Although ESCC and EAC are clearly different cancers, molecular findings within each tumor type hold promise in identifying subgroups with different responses to treatment. With the emergence of targeted therapies, recognizing how molecular differences between ESCC and EAC can be used to guide future trials and clinical treatment will be critical. Identification of ErbB2 and vascular endothelial growth factor amplifications has already led to the use of targeted therapies in advanced EAC. ${ }^{9,10}$ With the Cancer Genome Atlas results, we find ourselves at the Gates of Mordor and must decide whether to be Frodo, willing to throw the One Ring and the notion that one 
treatment rules them all into the fire, or to be like Gollum, jumping in after the ring refusing to let go.

\section{References}

1. Lagisetty KH, Beer DG, Chang AC. Squamous cell carcinomas and adenocarcinomas of the esophagus: one treatment does not rule them all. J Thorac Cardiovasc Surg. 2017; 154:1446-7.

2. Cancer Genome Atlas Research Network, Analysis Working Group: Asan University, Agency BC Cancer Agency, Brigham and Women's Hospital, Broad Institute, Brown University, et al. Integrated genomic characterization of oesophageal carcinoma. Nature. 2017;541:169-75.

3. van Hagen P, Hulshof MC, van Lanschot JJ, Steyerberg EW, van Berge Henegouwen MI, Wijnhoven BP, et al. Preoperative chemoradiotherapy for esophageal or junctional cancer. N Engl J Med. 2012;366: 2074-84.

4. Cunningham D, Allum WH, Stenning SP, Thompson JN, Van de Velde CJ, Nicolson M, et al. Perioperative chemotherapy versus surgery alone for resectable gastroesophageal cancer. N Engl J Med. 2006;355: $11-20$.
5. Ajani JA, D'Amico TA, Almhanna K, Bentrem DJ, Besh S, Chao J, et al. Esophageal and esophagogastric junction cancers, version 1.2015. J Natl Compr Canc Netw. 2015;13:194-227.

6. Ajani JA, D'Amico TA, Almhanna K, Bentrem DJ, Chao J, Das P, et al. Gastric Cancer, Version 3.2016, NCCN Clinical Practice Guidelines in Oncology. J Natl Compr Canc Netw. 2016;14:1286-312.

7. Altorki N, Harrison S. What is the role of neoadjuvant chemotherapy, radiation, and adjuvant treatment in resectable esophageal cancer? Ann Cardiothorac Surg. 2017;6:167-74.

8. Sjoquist KM, Burmeister BH, Smithers BM, Zalcberg JR, Simes RJ, Barbour A, et al. Survival after neoadjuvant chemotherapy or chemoradiotherapy for resectable oesophageal carcinoma: an updated meta-analysis. Lancet Oncol. 2011;12:681-92.

9. Bang YJ, Van Cutsem E, Feyereislova A, Chung HC, Shen L, Sawaki A, et al. Trastuzumab in combination with chemotherapy versus chemotherapy alone for treatment of HER2-positive advanced gastric or gastro-oesophageal junction cancer (ToGA): a phase 3, open-label, randomised controlled trial. Lancet. 2010;376:687-97.

10. Wilke H, Muro K, Van Cutsem E, Oh SC, Bodoky G, Shimada Y, et al. Ramucirumab plus paclitaxel versus placebo plus paclitaxel in patients with previously treated advanced gastric or gastro-oesophageal junction adenocarcinoma (RAINBOW): a double-blind, randomised phase 3 trial. Lancet Oncol. 2014; 15:1224-35 